\title{
ASSISTÊNCIA DE ENFERMAGEM NAS EMERGÊNCIAS PSIQUIÁTRICAS
}

Sônia Barros* Marli Alves Rolim"

BARROS, S.; ROLIM, M.A. Assistência de enfermagem nas emergências psiquiátricas. Rev. Esc. Enf. USP, v. 26, n. 2, p. 125-36, Ago. 1992.

A implantação de Serviços de Pronto Atendimento em Psiquiatria, em alguns Pronto-Socorros da cidade de São Paulo, nos últimos anos, foi que motivou a elaboração do presente trabalho. Inicialmente as autoras tecem algumas considerações sobre emergências psiquátricas para, posteriormente, fundamentadas em tais considerações, abordarem a assistência de enfermagem nessa área.

UNITERMOS: Emergências psiquiátricas. Assistência de enfermagem.

\section{INTRODUÇÃO}

A procura para atendimento de pacientes apresentando comportamentos indicativos de emergência psiquiátrica sempre ocorreu apesar de ainda não existirem postos de atendinento adequados para tal.

E sabido que os Pronto-Socorros dos grandes hospitais gerais recebem população merecedora de cuidados em saúde mental e que a ausência de serviços de emergência capazes de impedir o processo de cronificação da clientela, através da ređução do número de internações e da realização de intervenções terapêuticas de caráter intensivo, dificulta o bom funcionamento das unidades de assistência primária e secundária que requerem cobertura desse pronto atendimento (SÃO PAULO - Estado - s.d.; CESARINO - 1989).

Nos últimos anos foram criados, na cidade de São Paulo, serviços de pronto atendimento psiquiátrico em pronto-socorro, buscando atender essa população, com o objetivo, portanto, de conter a gravidade do quadro psiquiátrico do paciente e evitar a internação hospitalar.

Atualmente na região metropolitana de São Paulo existem serviços públicos que se caracterizam como serviço de pronto atendimento ou unidades de emergência, com leito de observação por até 72 horas

\footnotetext{
* Enfermeira. MIestre em Enfermagem. Assistente do Departamento de Enfermagem MaternoInfantil e Psiquiatrica da Escola de Enfermagem da USP - disciplina Enfermagem Psiquiátrica.
} 
a fim de possibilitar a intervenção terapêutica conforme a exigência de cada caso (SÃO PAULO - Estado - s.d.).

As unidades de emergência, em relação ao nível extra-hospitalar, no circuito de atenção à saúde mental, inserem-se como porta de entrada e retaguarda, tendo o hospital como sua unidade de referência para internações. Daí, operarem como instância de tratamento e triagem, direcionando a clientela para os espaços teoricamente adequados a responder à sua demanda e atenção, ao mesmo tempo em que res. pondem sua necessidade de urgência.

$O$ atendimento de pacientes em serviços de emergência psiquiátrica requer da enfermeira psiquiátrica brasileira uma nova abordagem da assistência do doente mental, uma vez que aí visualizamos um novo campo de prática dessa especialidade. Daí acharmos necessário abordar, inicialmente, no presente trabalho, conceitos de emergência psiquiátrica para melhor compreensão desta e das ações de enfermagem pertinentes à mesma.

Emergências psiquiátricas são todas aquelas condições clínicas em que um transtorno mental, agudo ou sub-agudo, vem causar uma alteração do comportamento, de tal gravidade, que coloca em risco a integridade física do paciente ou a de terceiros (BRASIL-Ministério da Saúde -1983 ).

Segundo a Associação Americana de Psiquiatria (APA), citada por MERCKER (1986) emergência psiquiátrica é uma situação que inclui um distúrbio agudo do pensamento, comportamento, humor ou relacionamento social que requer intervenção imediata, julgada necessária pelo cliente, família ou comunidade.

Entre os autores que se preocuparam em categorizar as emergências psiquiátrica, estão SOLOMON; PATCH (1975) que classificam as emergências psiquiátricas devido a causas psicogênicas e a não psicogênicas. O primeiro grupo inclui:

- tentativa de suicídio

- ameaça de suicídio

- tentativa de homicídio

- ameaça de homicídio

- comportamento agressivo

- estados de fuga

- PMD - forma maníaca

- crises domésticas

- reação de pânico, tipo ansioso

- reação de pânico, tipo hipocondríaco 
- depressão agitada

- distúrbios situacionais transitórios

- esquizofrenia paranóide

- excitação catatônica

Por outro lado, as emergências psiquiátricas devido a causas não psicogênicas seriam:

- alcoolismo agudo

- sensibilidade patológica ao álcool

- delirium tremens

- alucinose alcoólica

- abstinência de barbitúrico

- intoxicação por fenotiazinas

- reações e abstinência a outras drogas

- intoxicação por brometos

- drogas psicotomiméticas

- furor epiléptico

- epilepsia psicomotora

- hiploglicemia

- síndrome de hiperventilação

- tireotoxicoses, mixedema e doenças das paratiróides

- psicose pós-parto

- tumores cerebrais

- hematoma subdural

- psicose infecciosa

- doença de Addison

- Porfiria

Para estes autores é de extrema importância a diferenciação nestas duas categorias, uma vez que algumas desordens de origem não psicogênica podem pôr em risco a vida do paciente havendo, portanto, necessidade de diagnóstico preciso e terapia somática específica e imediata.

O "Joint Committee" da "American Hospital Association" e a "American Psychiatric Association", citados por SOLOMON; PATCH (1975), 
recomendam a seguinte classificação dos doentes mentais que necessitam de cuidados psiquiátricos de emergência:

1. doentes mentais que procuram ajuda ou que a aceitam voluntariamente (pacientes voluntários);

2. pessoas que inicialmente podem não aceitar os cuidados voluntariamente, mas que podem ser persuadidas para isso (pacientes persuadíveis) e,

3. pessoas resistentes que não aceitam cuidados voluntariamente $\mathbf{e}$ cujo comportamento pode se tornar real ou potencialmente perigoso para si ou para outros (pacientes resistentes).

Dentre os pacientes chamados voluntários incluem-se aqueles cujo comportamento é caracterizado por:

- ansiedade e pânico

- intoxicação alcoólica

- abuso de drogas

- depressão leve

No grupo dos pacientes chamados persuadiveis, encontramos aqueles pacientes cujo comportamento caracteriza-se por:

- depressão severa

- senilidade

- sintomas paranóides

Já, no grupo de pacientes denominados resistentes, incluem-se aqueles com comportamento caracterizado por:

- abstinência de álcool

- risco ou tentativa de suicídio

- agitação e agressividade

Por esta classificação, podemos perceber a importância da observação do comportamento apresentado pelo paciente para aferir a gravidade do quadro, bem como sua aceitação do tratamento.

É de extrema importância que, dentro do trabalho de equipe multiprofissional, o enfermeiro possa observar, descrever e fazer o diagnóstico de enfermagem do comportamento exibido pelo paciente, para assim traçar o plano de cuidados e contribuir para o alcance dos objetivos da unidade de pronto-atendimento - conter a gravidade do quadro, evitar a internação hospitalar e, assim, impedir o processo de cronificação do cliente.

No decorrer do processo de implantação dos serviços de emergên. cias psiquiátricas, as docentes da disciplina Enfermagem Psiquiátrica 
I da EEUSP receberam alguns pedidos de assessoria de enfermagem por parte da direção das instituições envolvidas neste processo. Foi a partir daí que entramos em contato mais direto com a problemática das emergências psiquiátricas.

Em 1989, as docentes da referida disciplina tiveram o oportunidade de, além de oferecer o conteúdo teórico sobre emergências psiquiátricas, levar os alunos da graduação para o campo prático em dois Serviços de Emergências. Em um deles, uma das docentes teve a oportunidade de participar, durante estes últimos anos, das discussões sobre a problemática dos recursos humanos e da organização de referido Serviço.

Frequientando as Emergências com os alunos, tivemos a oportuni dade de verificar que a assistência de enfermagem prestada passava longe daquela preconizada como a mínima necessária para o atendimento do doente mental.

O que presenciamos foi um quadro que nos mostrava pacientes restringidos no leito para facilitar os cuidados de enfermagem e não porque o seu comportamento assim o exigisse; sinais vitais sendo verificados apenas porque faziam parte da prescrição médica. As condições de higiene não só dos pacientes eram ruins, como também da enfermaria como um todo. Observamos também que as anotações de enfermagem não eram feitas de forma sistematizada e nem havia um canal estabelecido de comunicação entre os elementos da equipe. Chamou-nos a atenção, também, o fato de não termos percebido, enquanto estivemos presentes, a atuação do enfermeiro, quer na assistência direta ou indireta.

Ressaltamos que estas observações têm sido validadas pelos alunos quando fazem a avaliação de suas experiências nas Emergências.

Essas percepções apontam para uma das especificidades do aten. dimento em urgências psiquiátricas, enfatizadas por LUIS (1990), que é a importância da formação específica do profissional que atua nessa área.

Esses fatos, acrescidos da carência de bibliografia nacional de en. fermagem sobre o assunto, motivaram-nos a escrever o presente artigo, esperando contribuir assim para a melhoria da qualidade da assistên. cia de enfermagem nesses locais.

Com o intuito de facilitar a compreensão da assistência de enfermagem em uma unidade de emergência psiquiátrica, abordaremos, inicialmente, as medidas gerais que devem ser tomadas em qualquer situação e, posteriormente, descreveremos a assistência específica ao paciente com comportamentos que mais frequientemente provocam atendimento nas Unidades de Emergência da região metropolitana de São Paulo - o alcoolista - e também àquele que mais provoca medo e rejeição - agitado e agressivo (CESARINO. 1989). 
Ao escrever sobre a assistência de enfermagem nas Emergências, LUfS (1990) enfatiza que um dos aspectos importantes na prestação da assistência de enfermagem é a criação de ambiente terapêutico, entendido pela autora como um local sem estímulos, protegido pela enfermagem e com um mínimo de conforto. Acrescenta, ainda, que estabelecer diálogos com os pacientes pode colaborar para o ambiente terapêutico.

Baseadas em nossas experiências no campo de prática, no ensino de enfermagem psiquiátrica e em MANGLASS (1986), consideramos gerais as seguintes medidas que devem ser adotadas na prestação de assistência nas emergências psiquiátricas:

- Avaliar rapidamente a situação

- Servir de apoio ao paciente

- Ouvir cuidadosamente

- Pedir ajuda quando necessário

\section{Avaliar cuidadosamente a situação}

Antes de qualquer intervenção, faça uma análise da situação como um todo.

Avalie as condições físicas do paciente para verificar se este não corre perigo de vida ou necessita de alguma intervenção somática imediata.

Verifique se o paciente está muito ansioso ou agressivo antes de dar qualquer orientação ou mesmo tentar tranquiilizá-lo verbalmente. Lembre-se de que a ansiedade provoca diminuição da atenção, memória e orientação o que não permitirá ao mesmo memorizar ou lembrar-se de qualquer orientação que lhe seja feita ou mesmo dar informações muito complexas.

\section{Sirva de apoio ao paciente}

O propósito da emergência psiquiátrica é ajudar o paciente durante a situação de crise e não de se fazer um tratamento psicoterápico profundo.

Aproxime-se do paciente vagarosa e calmamente e transmita-lhe o desejo de ajudar. Isto pode ser feito, por exemplo, dizendo-lhe: "Ficarei ao seu lado por algum tempo e lhe farei algumas perguntas para saber como poderei ajudá-lo".

Seja objetivo; focalize sua atenção em informações que estão relacionadas à emergência. Tente desviar o discurso do paciente de assuntos irrelevantes e coloque em foco a idéia principal. Exemplo: "O Senhor estava me dizendo que tomou comprimidos e...". 
Enquanto questiona o paciente a respeito de seus problemas, valo. rize-o, relembrando-o de seus pontos fortes.

\section{Ouça cuidadosamente - Saber ouvir}

Ouça atentamente como o paciente percebe a situação pela qual passa. Sumarize o que ele disse a você, o que lhe dará a sensação do estar sendo compreendido.

Além das técnicas de comunicação terapêuticas, utilize a comuni. cação não-verbal para reforçar a mensagem de que você se preocupa com o problema dele - acene com a cabeça, olhe-o nos olhos e incline-se um pouco para ouví-lo.

Faces estranhas e rotinas não familiares podem contribuir para aumentar a ansiedade do paciente. Explique o que está ocorrendo à sua volta e dê-lhe tempo para fazer perguntas.

\section{Peça ajuda quando necessário}

Não hesite em pedir ajuda.

Não negligencie a sua própria segurança quando estiver tratando de um paciente potencialmente violento. Permaneça a uma certa distância do paciente, nunca lhe dê as costas e não o deixe entre você e a saída. Diga a um colega onde está indo com o paciente e peça-lhe para checar o local com certa frequiência.

Se o paciente resiste e, nem sua família e amigos podem ajudá-lo a conseguir sua cooperação e você percebe que não pode controlar a situação, chame os outros membros da equipe.

Violentos ou não, muitos pacientes que enfrentam situações de crise necessitarão de mais ajuda do que uma emergência está equipada para dar. Isto significa que você terá que arranjar algum tipo de seguimento.

Certifique-se de que o paciente tem alguém para acompanhá-lo e dar-lhe apoio antes de deixar o local.

\section{Medidas especificas}

Baseadas na nossa experiência e na literatura existente (BAYLEY; DREYER-1977; HOLBROOK et al. - 1977; MANFREDA-1977; TEIXEIRA et al.-1981; CARVALHO et al. 1985; BURGESS-1985), descreveremos a assistência de enfermagem específica para pacientes que apresentam comportamento caracterizados por intoxicação alcoólica e agitação e agressividade.

Assistência de enfermagem a pacientes com intoxicação alcoólica

Grande contingente de pacientes que procuram os Pronto-Socorros apresentam quadro de alcoolismo. 
Os estudos epidemiológicos realizados na população adulta, em vários países e também no Brasil, sugerem uma prevalência de 5 a 10\% de alcoolismo (Brasil - Ministério da Saúde - 1987).

A intoxicação alcoólica tem como características essenciais as mudanças de comportamento, devido à ingestão recente de considerável quantidade de álcool. Estas mudanças incluem agressividade, incapacidade de julgamento, euforia, depressão, labilidade emocional e outras manifestações de comprometimento do desempenho social ou ocupacional. Os sinais fisiológicos que podem ocorrer nesse quadro são: fala indistinta ou ininteligível, incoordenação, andar sem equilíbrio, nistag. mo e face avermelhada. Num quadro de maior intoxicação a pessoa pode até perder a consciência (BRASIL - Ministério da Saúde - 1987).

O paciente alcoolizado geralmente se apresenta à emergência porque a alteração de seu comportamento resultou em algum incidente (brigas, atropelamento) ou porque é trazido pela polícia.

\section{Avaliação}

É importante descartar outras condições somáticas que podem provocar comportamentos que se assemelham à intoxicação aguda por álcool. Pessoas que estão desorientadas, com incoordenação e cheiro de álcool, podem estar sofrendo de condições tais como hematoma subdural, outros traumas cerebrais, hipoglicemia, falência hepática, coma diabético, super dosagem de barbitúricos, psicose tóxica secundária à mistura de álcool e outras drogas.

Para essa avaliação é necessário que se faça, inicialmente, o controle dos sinais vitais e se procure evicências de trauma físico, tais como contusões, abrasões e lacerações.

É importante ainda obter-se, junto a familiares ou amigos que acompanham o paciente, dados de saúde - existência de doenças crônicas, outras drogas ingeridas ou disponíveis e história de quedas e traumatismo craneano, assim como a história sobre o hábito de beber do paciente - descrição do episódio, quanto consumiu de álcool, qual o comportamento quando bebe, se existe ingestão de alimentos.

\section{Intervenção}

Os problemas somáticos e traumas físicos devem ser imediatamente tratados.

A manifestação de comportamento inadequada deve ser controlada por meio de ambiente sem estimulo e, se necessário, restrições mecânicas leves.

$\hat{E}$ fundamental que o enfermeiro e o pessoal de enfermagem, que dão cuidados ao paciente, mantenham uma atitude não julgadora. Deve-se evitar rotular o cliente com palavras e frases tais como, "freguês", "bêbado de novo". 
Deve-se ter claro que tentativas de fazer o paciente raciocinar são, geralmente, ineficazes durante o estado de intoxicação. Deve-se agir de forma a controlar a situação rapidamente e então estabelecer diálogo com o cliente.

Quando o cliente estiver sóbrio, tentar providenciar informações sobre os efeitos do álcool, sobre outros problemas somáticos, e alter. nativas para lidar com ansiedade e tensão. Deve-se, ainda, informá-lo sobre os recursos para tratamento, na comunidade.

\section{Assistência de enfermagem ao paciente} com comportamento agitado e agressivo

Embora não tão frequientes, os episódios de agitação e agressividade, são talvez, as situações mais perturbadoras e destrutivas encontradas pelo pessoal, num serviço de emergência. Geralmente a pessoa é trazida até a emergência pela polícia e, então, já foi dominada de alguma forma. Mais difícil de tratar é a pessoa que apresenta um qua. dro de agitação e agressividade depois de chegar à sala de emergência.

Este comportamento pode aparecer em pacientes portadores de agravos psiquiátricos, como por exemplo, durante surtos psicóticos de Esquizofrenia e de Psicose Maníaco-Depressiva, e pacientes histéricos, epilépticos, bem como em pacientes internados em hospital geral, em situação de crise.

\section{Avaliação}

Deve ser feita muito rapidamente e os fatores a serem considerados imediatamente incluem identificar se a pessoa está armada, se o número de pessoas disponíveis é suficiente para conter o paciente e se outras pessoas estão em perigo.

\section{Intervenção}

Ao abordar a pessoa agressiva, o enfermeiro deve falar com a pessoa agressiva e continuar falando do começo ao fim do manejo da situação. Tenta-se transmitir, ao paciente, a expectativa de que a situação está sob controle e que, o fato dele acalmar-se é suficiente para finalizar a crise.

Os recursos humanos para esta assistência incluem o pessoal da sala de emergência psiquiátrica e, se necessário, o pessoal de outras áreas do Pronto-Socorro, guardas de segurança e, como último recurso, visitantes da sala de emergência.

Os parentes e amigos do paciente podem servir para acalmar ou inflamar a situação. Se a presença desta pessoa está acalmando, o 
enfermeiro deve fazer uso desta influência; se está agravando mais a situação deve-se removê-la da área tão rapidamente quanto possível.

$E$ inportante, ainda, ter ciência de que os problemas que as pessoas da equipe de enfermagem encontram ao cuidar do paciente são decorrentes, na maioria, da atitude das mesmas em relação às manifes. tações de agressividade.

A equipe deve ter claro, que se há perigo imediato para a pessoa agressiva ou para os outros, ela deve intervir, indiferente ao risco pessoal; se a violência destrói somente equipamentos, a equipe deve intervir quando isto pode ser feito sem riscos pessoais. Deve-se, tão rapidamente quanto possível, remover outras pessoas que possam estar em perigo.

Se as tentativas iniciais de intervenção verbal não forem suficientes, o enfermeiro e equipe devem mover-se rapidamente para obter medidas físicas que o auxiliem. Quando é óbvio que o controle físico é necessário, deve-se limitar o alcance dos movimentos do paciente.

Deve-se administrar a medicação prescrita, para o controle do comportamento. A restrição física deverá ser mantida até que a medicação faça efeito. É necessária a manutenção de controle de sinais vitais, uma vez que é frequiente a hipotensão como efeito colateral dos tranqüilizantes.

Se a medicação não controlar suficientemente o comportamento do paciente, deverão ser usadas as restrições mecânicas, com as precauções e cuidados necessários.

A equipe de enfermagem deve lembrar que o paciente agitado e agressivo está incapaz de controlar essas manifestações, provocando medo e rejeição nos que o rodeiam, o que gera exacerbação daquelas manifestações.

A assistência de enfermagem descrita neste trabalho se refere apenas aos cuidados iniciais a pacientes atendidos em um serviço de emergência psiquiátrica. $E$ importante ressaltar que após o atendimento imediato do paciente e, quando este permanecer em observação nas enfermarias, a enfermeira desempenhará outras atividades, decorrentes de suas funções, tais como observação e descrição de seu comportamento, intervenção em crise, uso das medidas terapêuticas em enfermagem, atendimento de suas necessidades básicas, orientação ao paciente e seus familiares, entre outras.

BARROS, S.; ROLIM, M.A. Nursing care in the psychiatric emergency room. Rev. Esc. Enf. USP, v.26, n. 2, p. 125-36, Aug. 1992.

The emergency psychiatric services implantation in general hospitals, at São Paulo City, motived the authors to write this article. They present some considerations about psychiatric: emergencies and the main points in nursing care of the client in $a$ crisis intervention setting.

UNITERMS: Psychiatric emergency. Nursing care. 


\section{REFERENCIAS BIBLIOGRAFICAS}

BAYLEY, D.S.; DREYER, S.O. Therapeutic approaches to the care of the mentally ill. Philadelphia, Davis, 1977. cap. 10, p. 137-47: Agressive behavior.

BRASIL. Ministério da Saúde. Secretaria Nacional de Programas Especiais de Saúde. Divisão Nacional de Saúde Mental. Manual de orientąão para uso de psicofármacos. Brasillia, 1983.

Programa Nacional de Controle dos Problemas Relacionados com o Consumo de Alcool (PRONAL) Manual de normas e procedimentos. Brasilia, 1987.

BURGess, A.W. Psychiatric nursing. 4.ed. New Jersey, Prentice-Hall, 1985, cap. 14, p. 317-50: Mood disorders.

CARVALHO, D.W. et al. Assistência de enfermagem a pacientes com manifestações de distúrbio emocional, internados em unidade médico-cirúrgica. Rev. Paul. Enf., v. 5, n. 1, p. 32-7, 1985.

CESARINO A.C. Uma experiência de saúde mental na prefeitura de São Paulo (Projeto de Açðes Integradas de Saúde Mental na zona norte do Município de São Paulo: uma gestão democrática de um projeto público de Saúde Mential). In LANCETTI, A. Saúdo loucura. São Paulo, Hucitec, 1989, p. 3-32.

HOLBROOK, B. et al. Agression: a diferent approach. Nurs. Mirror, v. 144, n. 16, p. 45-8, 1977.

LUfs, M.V. Enfermagem em urgências psiquiátricas: relato de uma experiência assistencial e de ensino. Enfoque. v. 18, n. 2, p. 39-43, 1990.

MANFredA, M.L. Psychiatric nursing. 5.ed. Philadelphia, Davis, 1977. cap. 34, p. 417-26: Moods of elation and depression in affective behavior nursing care.

MANGLASS, L. Psychiatric interventions you can use in an emergency. RN, v. 49, n. 11, p. 38-9, 1986.

MERCKER, M.S. Psychiatric emergency evaluation. Nurs. clin. North Am. v. 91, n. 3, p. 387-96, 1986.

SĀo PAULO (Estado). Secretaria de Estado da Saúde. Centro de Apoio ao Desenvolvimento da Assisténcia Integral à Saúde. Organização da saúde mental a nivel regional no Sistema Unificado de Saúde. (SUDS). São Paulo, s.d./mimeografado.

SOLOMON, P.; PATCH, V.D. Manual de psiquiatria. São Paulo, Atheneu/EDUSP, 1975. p. 368-7: Emergências psiquiátricas.

TEIXEIRA, M.B. et al. Assistência de enfermagem a pacientes com comportamento caracterizado por manifestaçōes de agitaçăo e agressividade. Rev. Esc. Fnf. USP, v. 15, n. 2 , p. 141-6, 1981. 